\title{
Understanding varve formation processes from sediment trapping and limnological monitoring
}

Antti E.K. Ojala', C. Bigler² and J. Weckström³

\begin{abstract}
Sediment trapping and monitoring is essential for paleolimnological research. It has allowed us to understand the seasonal deposition of the abiotic and biotic components within varved lakes in Sweden and Finland, thus providing a basis for paleoenvironmental interpretations.
\end{abstract}

Varved sediments are rich and detailed archives of paleoenvironmental information. Interpreting these archives correctly requires that the sedimentological processes leading to the varve deposition and their controlling factors are known, understood and quantified. Modern lake research, particularly when dealing with seasonally to annually resolved varved sediments, combines limnological monitoring, sediment trapping and sediment analysis (Leemann and Niessen 1994; Bigler et al. 2012; Ojala et al. 2013). The reason for such an integrative approach is to understand to what extent the sediments and its components reflect the ongoing sedimentary and biogeochemical processes within a lake basin (Ryves et al. 2013). Monitoring and trap studies also enable us to better understand the seasonal information within a varve (i.e. definition of a local varve model) and effectively calibrate varves and paleolimnological proxies against instrumental hydrological and meteorological data.

\section{Varve formation}

For proglacial lakes with clastic varves (Leemann and Niessen 1994; Lamoureux 1999) and Boreal lakes with clastic-biogenic varves (Renberg 1982; Zillén et al. 2003; Ojala et al. 2000), the deposition of varves is a function of hydrometeorological parameters, in particular seasonal runoff and the associated discharge of suspended sediment from the catchment into the depositional basin. However, as discussed by Lamoureux (2012), the deposition of allochthonous clastic material is also affected by limnological and geomorphological features, which determine sediment pathways to deposition and the yield from the catchment area. Understanding these processes through monitoring and sediment trapping is a prerequisite for the correct interpretation of physical varve data and their calibration against instrumental observations. Awareness that many varved records in Europe and North America contain both a climate-environmental as well as a superimposed local anthropogenic signal has focused scientists on gaining more comprehensive information on the ongoing sedimentary processes in these lakes (Snyder 2012; Stockhecke et al. 2012; Tylmann et al. 2012; Ojala et al. 2013).

Based on three years of monitoring data on seasonal particle pulses in Lake Van in Turkey,

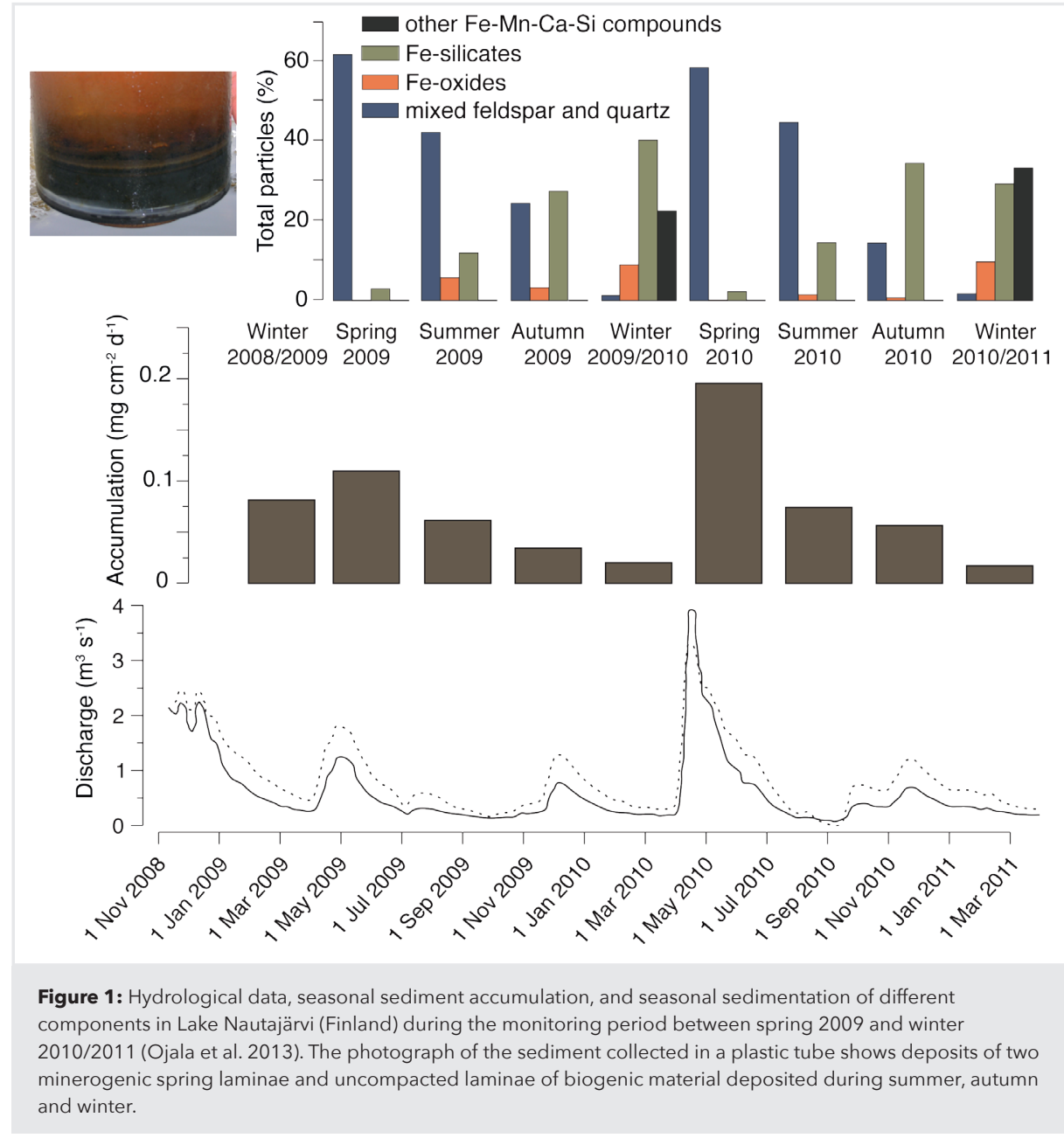

Stockhecke et al. (2012) were able to show for the first time that the seasonal particle flux is linked to hydrological and meteorological forcing, which is ultimately controlled by atmospheric circulation patterns. They demonstrated pronounced temporal and lateral variations in suspended-matter concentration within the lake, providing a basis for the reconstruction of past seasonal climate patterns based on the varved lithology.

In the Finnish boreal forest zone, Ojala et al. (2013) have monitored the seasonal accumulation patterns of allochthonous clastic material and organic remains in Lake Nautajärvi, which contains a nearly 10,000-year-long continuous record of clastic-biogenic varves (Ojala and
Alenius 2005). Comparison of the seasonal sediment fluxes between the climatologically and hydrological different years of 2009 and 2010 showed that the seasonal fluxes recorded in sediment traps correspond with environmental changes. Deviation in seasonal accumulation was most apparent in the rate of spring deposition of allochthonous mineral matter and less pronounced for summer, autumn and winter sediment fluxes (Fig. 1).

\section{Sediment flux and deposition}

Sediment fluxes undergo burial, compaction and various bio-geochemical changes before being preserved as a sedimentary deposit. Understanding the spatial and temporal variability of these processes is essential for a reliable 

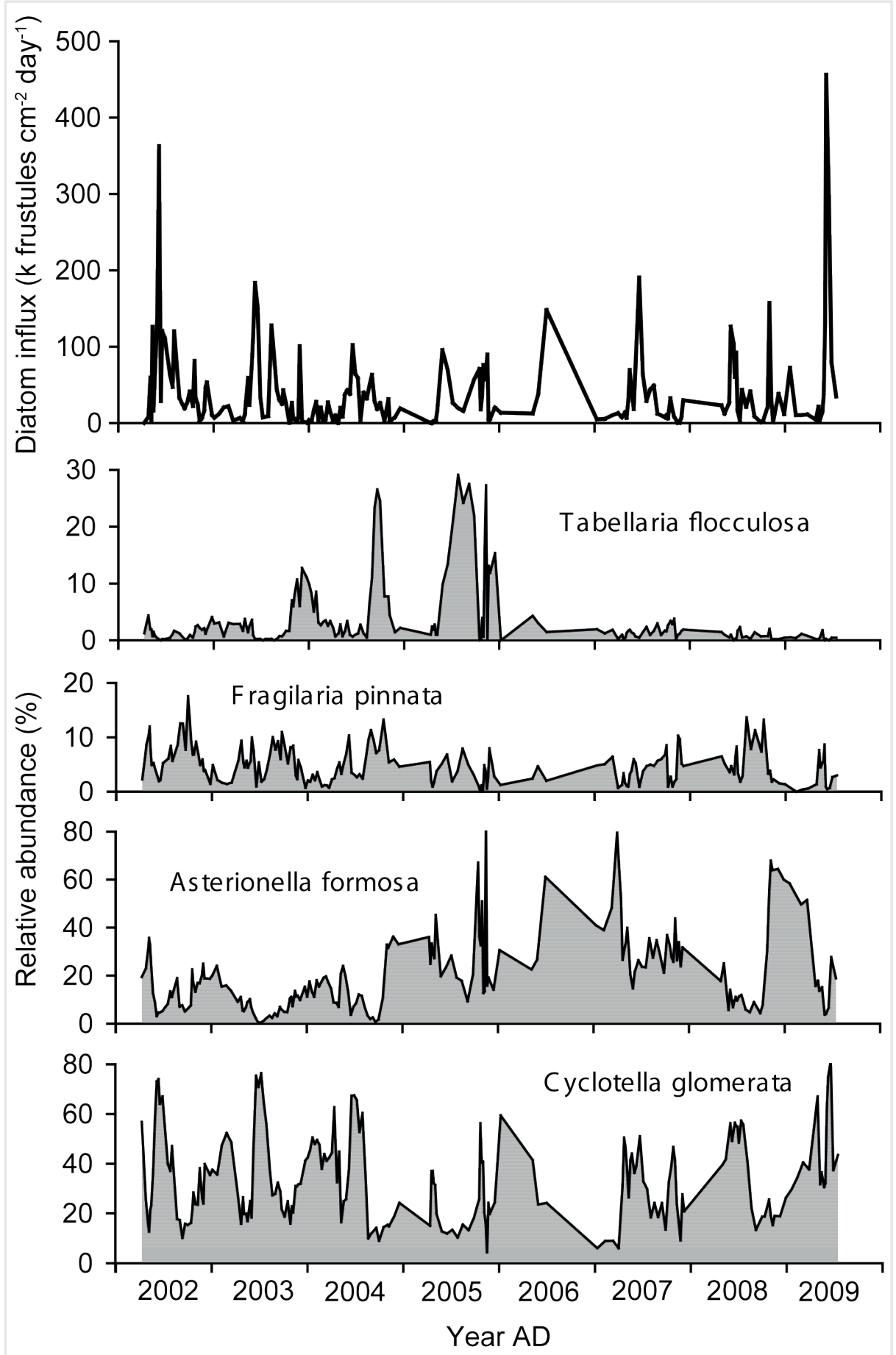

Figure 2: Total diatom influx and relative abundance of major diatom taxa in Nylandssjön since 2001 based on sediment trap data (Bigler et al. 2012).

interpretation of any sediment record. Since 1979, Renberg (1986), Petterson et al (1993) and Gälman et al. (2006) have collected >15 freeze-cores from Lake Nylandssjön (northern Sweden) and analyzed the clastic-biogenic varves in order to quantify the sedimentation processes. Their study showed that sediment compaction is most rapid in the first years after deposition, i.e. varve thickness decreases by about 60\% within five years (Maier et al. 2013). At Nylandssjön the rate of compaction is linked to a loss of pore water, but despite compaction, the initial signal of varve thickness variations was preserved following burial and compaction. Similarly, the concentration of carbon and nitrogen in the sediment decreased by $20 \%$ and $30 \%$, respectively, within the first five years after deposition, but only $23 \%$ and $35 \%$ after 27 years (Gälman et al. 2008). The study also demonstrated that this process affected the stable isotope ratios of $\delta^{13} \mathrm{C}$ (increase over time) and $\delta^{15} \mathrm{~N}$ (decrease over time) (Gälman et al. 2009).

\section{Deposition of biotic indicators}

The biotic component of varved sediments provides additional paleoenvironmental paleoecological information if its accumulation and deposition dynamics is understood. From a sedimentological perspective, Simola (1977) was a pioneer in verifying the annual character of seasonal laminae based on diatom succession in the biogenic varves of Lake Lovojärvi, Finland. Recently, Ojala et al. (2013) found that in Lake Nautajärvi, Finland, the sedimentation processes differ substantially between abiotic and biotic components: the abiotic fraction is predominantly of allochthonous origin, whereas the biotic fraction is mainly of autochthonous origin. This has a great impact on the relative proportions of abiotic and biotic components as aquatic biota are more dependent on seasonal processes (e.g. spring and autumnal overturns) than on rapid, short-lived environmental episodes, such as the spring snowmelt discharge-peak. So the accumulation rates of, for instance, diatoms and chrysophyte cysts in Lake Nautajärvi revealed firstly, very similar inter-annual trends despite different climatic conditions between the two studied years, but secondly, distinctive differences between the seasons of a same year (Ojala et al. 2013).

Similarly, the diatom record from Lake Nylandssjön, northern Sweden, is dominated by the same recurring set of diatom taxa every year, as observed in plankton survey-data, sediment traps and varved sediments. However, the dominant taxa show different abundance patterns from year to year. The abundance pattern of a certain diatom taxa is seemingly independent of other diatom taxa, and not obviously explained by a single environmental factor (Fig. 2; Bigler et al. 2012). This indicates complex interaction of physical (e.g. temperature, stratification, ice-cover), chemical (nutrient concentrations, water quality) and biological (life cycles, grazing pressure) processes controlling biological signal formation on an annual basis. The above examples demonstrate that sediment trap studies can provide essential information to understand the sedimentation processes that control to the generation of varved lake sediments. This, in turn, enables us to extract the paleoenvironmental signal from these high-resolution sediment archives with greater confidence.

\section{AFFILIATIONS}

${ }^{1}$ Geological Survey of Finland

${ }^{2}$ Department of Ecology and Environmental Science, Umeå University, Sweden

${ }^{3}$ Department of Environmental Sciences, University of Helsinki, Finland

\section{CONTACT}

Antti E.K.Ojala: antti.ojala@gtk.fi

\section{SELECTED REFERENCES}

Full reference list under:

http://www.pages-igbp.org/products/newsletters/ ref2014_1.pdf

\section{Bigler C et al. (2012) Terra Nostra 1012(1): 25-27} Gälman V et al. (2006) J Paleolimnol 35: 837-853 Maier DB et al. (2013) GFF 135: 231-236 Ojala AEK et al. (2013) GFF 135: 237-247 Stockhecke M et al. (2012) Palaeogeog Palaeoclimatol Palaeoecol 333-334: 148-159 